\title{
PERCURSOS DA LEITURA ENTRE A PÁGINA E A TELA: UMA MULTIPLICIDADE DE SENTIDOS
}

\author{
Débora Cristina Santos e Silva* \\ Keila Matida de Melo Costa*
}

\begin{abstract}
RESUMO: Este artigo, ao traçar um esboço das práticas sociais de leitura, propõe uma discussão sobre as condições de produção e recepção do texto digital. Para isso, focaliza a relação estabelecida entre o leitor e o texto nas experiências de leitura analógica e digital, avaliando suas especificidades diante da materialidade do texto e de sua configuração, em cada um desses suportes. Considera as múltiplas construções de sentido possíveis ao leitor em contato com o texto, tendo em vista a maneira como ele apreende o texto impresso e de como isso se altera quando se trata do texto em suporte digital, uma vez que, nesse caso, a interligação texto e leitor é mediada por tecnologias que favorecem a convergência de mídias, além de intensificar a experiência de interação do leitor com o texto e a interface.
\end{abstract}

PALAVRAS-CHAVE: Leitura. Texto impresso. Texto digital. Leitor. Interatividade.

\section{Introdução}

No intuito de discutir a relação entre leitor e texto e a multiplicidade de sentidos construídos nas interfaces da leitura, este ensaio remonta a momentos pontuais da história do texto em suas diferentes materialidades. Com efeito, é a partir desta ação de revisitar o passado - configurado como registro de uma história do livro que se torna possível compreender melhor as condições de produção e recepção do texto digital. Em alguns momentos deste trabalho, as materialidades impressa e digital - se confundem, uma vez que mescladas por um entendimento de linguagem que se desenraíza de certa concretude, colocando em cena uma determinada compreensão de prática leitora. Em outros, nitidamente se expressam peculiaridades que mostram as páginas viradas, lançadas ainda como desafios de um passado recente da história do livro e da leitura.

Nesta seara um tanto movediça, este ensaio objetiva pensar a relação leitor-livro nos meandros entre o mundo do texto e a realidade histórica e social. Para tanto,

\footnotetext{
*Universidade Estadual de Goiás. desants@uol.com.br

*Universidade Federal de Goiás. k mcosta@hotmail.com
} 
divide-se em duas partes. Na primeira, esboça aspectos da história da leitura no ocidente, focalizando a prática da leitura no ambiente escolar e buscando apontar a amplitude de uma história que não apenas abarca certas materialidades, mas que destaca valores e compreensões de mundo, construídos socialmente, os quais mediam a intervenção do sujeito na realidade. Na segunda, se por um lado exemplifica experiências de leitura que comungam ou desassociam as materialidades impressa e digital - cujas intervenções são realizadas por ferramentas gestadas no ambiente virtual -, por outro, focaliza as transformações geradas na relação entre leitor e texto na era digital.

\section{A leitura numa dimensão histórica: percursos do leitor}

Inicialmente, para compreender melhor os percursos traçados pelo leitor em sua relação com o texto oral e escrito, desde suas origens, abriremos um parêntese para mencionar aqui as reflexões de Pierre Lévy, que, em 1990, já discutia, ao traçar a trajetória das linguagens oral, escrita e digital, as transformações que as tecnologias provocam, por meio das linguagens que imprimem no espírito humano. Em seu texto, intitulado Os três tempos do espírito, o autor apresenta primeiramente o perfil das civilizações nômades, que viveram sob o signo da oralidade primária, baseada essencialmente no mito - este, por sua vez, identificado como um instrumento de inscrição que constituía a memória dessas sociedades por meio de estratégias mnemônicas, tais como a personificação, a dramatização, os cantos, as danças e as narrativas orais. Nesse nível de apreensão, as habilidades cognitivas mais exploradas eram a atenção, a percepção e a memorização.

Com o aparecimento da escrita, já no contexto das sociedades agrícolas, a história humana passou a se inscrever no papiro e na argila, donde a curiosa origem da palavra "página", que vem de pagus, do latim "campo do lavrador" (LÉVY, 1990, p. 112). Nesse novo contexto tecnológico, intensificado posteriormente pelo aparecimento do alfabeto, na Grécia dos anos 700 a.C., e da imprensa, no século XV, a palavra escrita passou, então, a inspirar o "sopro na argila", tornando-se a força propulsora do novo mundo que aparece com o 
registro do tempo histórico, uma vez que, ordenando o caos, estabelece marcos e define fronteiras, rompendo o devir, próprio do tempo mítico.

Diferentemente dessa hipótese de "ordenação do caos", Nora (1993) assevera que a perda de um saber herdado pela tradição, mesmo que fundamentado em conhecimentos míticos, implicava a construção dos lugares de memória. O autor especifica esses lugares como museus, bibliotecas, arquivos, dentre outros, e por eles é possível pensar também a escrita, por suas particularidades. A escrita comunga poder e saber e estabelece uma relação entre tempos históricos. Por ela, o passado pode ser desvelado e o presente, ressignificado. Desse modo, a escrita, desde o seu advento, é um lugar de memória e de história. E, se a materialidade em que a escrita se ampara resulta de transformações sociais, assim como essas transformações acarretam mudanças nessa materialidade, tais transformações não se efetivam como ruptura, mas como continuidade, ou seja, como modos de intervir e de estar conectado com o mundo próprio de cada época.

Relativamente a essa questão, Ferrari (2010) assinala que a Grécia antiga já suscitava essa discussão sobre as diferenças entre a oralidade e a escrita em seu potencial de ampliar a memória, prolongar a reflexão e sistematizar o pensamento. Em defesa da oralidade, Platão destacava a capacidade dialógica do discurso oral, que permite a participação direta do interlocutor, possibilitando a construção coletiva do saber. Por outro lado, Aristóteles defendia a escrita pela necessidade de fundamentação teórica e sistematização do conhecimento, sendo esta a concretização de um gênero textual mais rigoroso que a liberdade da poética e do diálogo. Nesse âmbito, assinala, ainda, Ferrari (2010, p. 73):

Tanto as ideias de Platão como as de Aristóteles se perpetuaram na contemporaneidade [...] [A] cultura da oralidade demonstra uma sociabilidade em que as mediações sejam capazes de expor o jogo simbólico, do poético, da presencialidade, do diálogo, de obras abertas, com autorias colaborativas, como contraponto à tradição escrita, que traçou um perfil em torno da lógica, da ciência, do controle do autor e da autoridade como obras fechadas. 
Efetivamente, a opção pelo predomínio cultural da escrita se justifica por sua estabilidade em descrever, narrar e dissertar sobre a realidade, com forte apelo instrucional. Ainda na tradição judaico-cristã, se reafirma a força da escrita pela "autoridade das escrituras", da autoria divina do texto, pela própria sacralização do livro (a Bíblia Sagrada). Por seu turno, a modernidade recorreu à autoridade do discurso científico, largamente difundido pelo livro, com a invenção da imprensa, e contando com a escrita como forte aliada para a consolidação dos modernos Estados europeus.

Isso corrobora as reflexões de Lévy, no texto mencionado, quando ele afirma que as transformações que as tecnologias da escrita provocaram nas manifestações da linguagem em seus diferentes suportes não foram substituídas completamente, mas permanecem convivendo entre si, nas práticas de leitura e escrita, até hoje. A oralidade, desse modo, não foi substituída pela escrita, nem esta pela linguagem digital. Todas elas se interrelacionam e, muitas vezes, coexistem num mesmo espaço e tempo. Ainda se mantêm, atualmente, significativas experiências de leitura e produção oral, a exemplo da literatura de cordel, dos causos populares e da "contação" de histórias. E muito mais que isso: textos orais se encontram materializados na escrita e vice-versa.

Do mesmo modo, não faz sentido fomentar discussões sobre a hipótese do "desaparecimento do livro", a partir de sua substituição por suportes digitais. O livro impresso deve permanecer ainda por muito tempo, até porque é uma das tecnologias mais consistentes, seguras e duráveis já inventadas pela humanidade. Por outro lado, mesmo que desapareça a forma impressa do livro, a concepção, o conceito, o constructo cultural que ele significa, certamente permanecerá existindo, ainda que em formato digital, em outros suportes. Isso evidencia que o livro possui uma história, e é essa história que dá sentido a todo um processo de evolução da própria humanidade.

Como resultado desse processo, a leitura assumiu sentidos diferenciados no decorrer dos tempos, na medida em que sua efetivação estava vinculada a um suporte, a uma forma de entender a sociedade. Se, em determinados tempos 
históricos, a leitura demandava a ocupação de um lugar e a manifestação de um corpo pelas mãos que permitiam o desenrolar do próprio texto, posteriormente esse quadro se altera. A fluidez do lugar e do tempo, por exemplo, vai inferir uma relação mais ampla do leitor com o texto, a qual é gerada pelo advento da tecnologia.

Ler um texto no início do século $\mathrm{XI}$, no Ocidente, era um grande desafio. $\mathrm{O}$ entendimento do texto só era permitido pela oralização, pois ele era um bloco compacto destituído de separação entre palavras, do uso de pontuação, de letras maiúsculas e minúsculas e da distinção entre parágrafos, como mostra Marquilhas (1999). Para a compreensão do texto, a oralização era, portanto, exigida. Essa prática do ato de ler também foi entendida como "publicização" de um texto. Um leitor lia para tantos outros leitores-ouvintes, numa dinâmica de socialização em que, inclusive, enquanto os demais ouviam o texto, trabalhavam. Quantas realidades foram transformadas em função da propagação de ideias pela oralização de um texto que alcançava leitores que não possuíam o domínio do ler e do escrever? A leitura, desse modo, não se restringia ao alfabetizado, como não se restringe até hoje. A leitura ganhava dimensão não limitada a certos espaços e tempos, pois quaisquer que tenham sido os sentidos dos textos lidos ou ouvidos, tais sentidos fluíam em outros tempos e lugares, à semelhança do papel da própria linguagem oral.

Desse modo, a ausência de escolarização não impedia que ideias se propagassem, que leitores se formassem de outros modos e de muitas maneiras. Situação que justificava a "tutelagem" da leitura em função de seu pronunciamento e do sentido que ela poderia gerar. Oralizar, então, exigia manter sob controle o que se lia. Práticas de leitura conjuntas, feitas sob a custódia geralmente masculina - a exemplo da figura emblemática do pai, do selecionador ou do censor - tinham essa pretensão. Na escola, a seleção dos livros e a tutela do professor também delimitavam sentidos. A leitura era oralização e socialização; lia-se em espaços públicos e privados: no ambiente do lar, "nos salões, nas sociedades literárias, nas carruagens ou nos cafés" (CHARTIER, 2009, p. 143). Por meio dela, outras práticas, outras experiências, novos textos 
eram demandados, mas a leitura, enquanto oralização, assumia uma entonação prescritiva quando adentrava a instituição escolar.

Efetivamente, a leitura como experiência de oralização - reprodução do discurso alheio, à semelhança do que ocorria com a escrita - tinha a pretensão de formar leitores e escritores alheios à realidade, já que ler era professar um texto pronto, dado e acabado, assim como escrever era reproduzir a escrita tal qual o modelo. O leitor, desse modo, era compreendido como sujeito pronto e acabado. O eixo de valorização na relação estabelecida entre leitor e texto era o do próprio texto, pois era dele que a voz era emanada. Era do texto que diferentes instâncias eram instauradas, como é possível visualizar numa das experiências de iniciação à leitura de Jean-Paul Sartre, descrita por Pompougnac (1997, p. 18-19):

\begin{abstract}
Anne-Marie fez-me sentar diante dela, em minha cadeirinha: inclinou-se, baixou as pálpebras, adormeceu. Desse rosto de estátua saiu uma voz de gesso. Fiquei tonto: quem estava contando a história? O quê? E a quem? Minha mãe estava ausente: nem um sorriso, nem um sinal de conivência; eu estava exilado. Além disso, eu não reconhecia sua linguagem. De onde ela tirava toda aquela firmeza? Após um instante, eu compreendi: era o livro que falava.
\end{abstract}

Na relação estabelecida entre a mãe de Sartre e o ouvinte-leitor, o estranhamento se evidencia. Se, de um lado, ele se apresentava exilado e ela, ausente; de outro, era o professar das palavras oriundas do livro que iria promover sentidos não pretendidos. Nos meandros entre sonoridade e significado, palavras ganhavam cores, mostravam-se cantantes, entrecortadas, sussurrantes. A descoberta do sentido do texto pelo leitor foi ocasionada por um dizer. Os sentidos construídos ganharam outra dimensão, na medida em que não ficaram restritos aos limites e aprisionamentos das palavras.

Essa extensão da prática da leitura oralizada, entretanto, não era um exercício corriqueiro, uma ação ordinária na formação de leitores no início do século XX em escolas brasileiras. Leite e Oliveira (2004) assinalam que, até a década de 1960, ler era oralizar. Nesse cenário, o texto possuía sentido estático, cabendo ao leitor "recuperá-lo". Na relação texto e leitor, o que prevalecia era a reprodução do que 
estava ali manifestado. Somado a isso, nesta recuperação, trabalhavam-se maneiras "corretas" de se praticar a leitura, tal como a entonação de voz e a postura ao se ler. Não era qualquer texto que servia ao "ensino". Os modelos eram calcados na reprodução das "boas" leituras dos "bons" autores. Isso não apenas reafirmava o discurso ali impresso, porque o disseminava, mas também dava a esse discurso notoriedade pelo lugar de onde ele advinha - da instituição escolar.

Inúmeros "autores-heróis" foram, por esse caminho, criados (BARBOSA, 2001). Autores que, inclusive, transformaram a sociedade pelo poder que exerceram sobre ela em função da legitimidade que suas escritas assumiram na realidade. São os exemplos de Monteiro Lobato, Olavo Bilac, Machado de Assis, dentre outros, que tiveram seus discursos amplificados pela mitificação que recaía sobre suas produções, as quais se tornavam não apenas veiculadoras de valores aceitos e almejados por uma sociedade que se desenvolvia e se "modernizava", mas também sinalizadoras de uma modificação social mais ampla, que abarcava prática de leitura e transformação social.

$\mathrm{Na}$ relação estabelecida entre leitor e texto, outro eixo de sustentação foi defendido por Leite e Oliveira (2004): o leitor. Para os autores, após a década de 1970, defendeu-se, na escola, que ler era elaborar, a partir do conhecimento prévio do leitor, o sentido do texto. $O$ texto não mais era detentor da "chave interpretativa". Caberia, agora, ao leitor tal tarefa. Essa defesa resultava no relativismo dos sentidos criados pelos alunos a partir dos textos, pois não havia a hipótese de o texto, pelo papel do autor, também dizer alguma coisa. A valorização de um eixo emudecia os demais. Posteriormente, o advento de outros estudos gerou nova conotação para a compreensão da leitura no ambiente escolar.

Ler passou a ser entendido como interação verbal e social do leitor com o outro, com o mundo; interação esta, mediada pela linguagem. Certamente, a leitura não mais seria interpretada simplesmente como operação mental de um leitor que se 
debruçava sobre o texto, muito menos como produção de sentido a partir simplesmente do texto, como afirmam os autores. Para eles:

\begin{abstract}
O sujeito, ao ler, além de construir sentidos ao que vê escrito, constituise na leitura, modifica sua visão de mundo e a si mesmo. Nesse espaço interlocutivo, propiciado pela leitura, o leitor entra em contato com diferentes significações atribuídas pelo autor, tem acesso a um meio de cultura e informação privilegiado socialmente, o que possibilita ampliar sua visão de mundo, transformá-la, transformando a si mesmo. (LEITE; OLIVEIRA, 2004, p. 20-21)
\end{abstract}

A leitura, nessa perspectiva, passa a ser entendida como prática social, uma vez que nela e por ela o leitor tem contato com o que historicamente foi construído acerca da língua e da própria sociedade; e nesse fluxo discursivo ele se integra e participa. Bakhtin (2009), ao dialogar com correntes linguísticas em voga no início do século $\mathrm{XX}$, como o objetivismo abstrato e o subjetivismo idealista, afirma que não é possível apreender o funcionamento real da linguagem se o direcionamento for ora no sistema ora no sujeito falante. Para o autor, o sujeito se constitui como tal na relação que estabelece com o outro, consigo mesmo e com o mundo, por meio da linguagem. O leitor, como sujeito histórico e social que é, constrói a língua e é influenciado por ela também, nesta dimensão: uma língua que se realiza por gêneros textuais que se alteram no decorrer dos tempos, mas que guarda entre si muitas semelhanças. Ler, desse modo, é estabelecer um diálogo entre leitor, autor, texto e mundo, numa imensa trama discursiva.

Se a discussão sobre leitura envolvia determinados eixos, para Chartier (2009), ela abrangia certas práticas decorrentes de mudanças sociais e de alterações na materialidade da escrita. Para ele, as formas de lazer e de sociabilidade que permitiam uma prática de leitura oralizada foram reduzidas a alguns espaços institucionalizados, porque a própria dinâmica do mundo moderno, das transformações urbanísticas, acarretou outras formas de ler em sociedade, como a leitura silenciosa. Essa prática gerava outro perfil de leitor e uma nova ocupação espacial. Chartier (2009) assegura que a leitura oralizada garantia a relação entre leitor e comunidade. Já a leitura silenciosa, feita "em espaço público (a biblioteca, 
o metrô, o trem, o avião)", era "uma leitura ambígua e mista" (CHARTIER, 2009, p. 143).

A relação entre público e privado teve no livro, no desenvolvimento da produção impressa e da materialidade da escrita, seu eixo de sustentação, uma vez que, pelo livro, o leitor se isolava do mundo, mesmo estando em espaço público. Tratase de um isolamento penetrável, contudo, conforme o autor. Soma-se a isso o fato de a liberdade cerceada pelo dizer do texto, por meio da oralização, ter sido rompida, pois a leitura silenciosa era o habeas corpus do leitor, como defende Certeau (2005). Tal prática exigia, todavia, domínio da leitura, já que ler silenciosamente pressupunha certa particularidade e autonomia. Inclusive, o ler silenciosamente na escola impunha não ruminar ou sussurrar, na medida em que nem o movimento dos lábios era permitido ${ }^{1}$. A leitura efetivada no corpo mantinha a custódia do leitor.

O silenciamento do texto talvez jamais tenha sido verdadeiramente concretizado. Pode ter sido, na verdade, controlado. O não pronunciar das palavras não garantia, pelos modos de ler, uma ausência de leitura. No silêncio, se avistava um leitor compenetrado, perdido no texto que lia - distante, lamentoso, choroso ou risonho - frente à história que lia. Os leitores eram rotulados como maduros ou imaturos, pela forma como apreendiam o texto a que tinham acesso. Nesse contexto, os romances eram perigosos, principalmente para os considerados leitores ingênuos, a exemplo das mulheres. O temor era que esses leitores pudessem seguir práticas concretizadas nas próprias narrativas, à modelo de Don Quixote e Madame Bovary, subvertendo, por exemplo, os valores morais.

Com efeito, a leitura do romance também instaurava uma ordem - a ordem burguesa. Por isso, no interior da casa burguesa, no espaço privativo do lar, a mulher permanecia absorta na leitura! Tal imagem, por muito tempo, diferenciou leitores de não-leitores. E pode ser que diferencie ainda nos dias de hoje, já que o

\footnotetext{
${ }^{1}$ Melo (2007) destaca tais práticas em espaços formais e informais de leitura na capital construída no sertão de Goiás - Goiânia.
} 
ser leitor se ampara em certos ícones. Nas pinturas europeias, o estereótipo da leitora foi descrito da seguinte forma:

\begin{abstract}
Leitora ávida, ela está cercada de outros livros, um dos quais aberto e deixado no chão, permitindo-nos supor que seu interesse pela leitura a faz percorrer varias obras ao mesmo tempo. A pequena estante colocada ao lado do sofá contém outros livros, de maior tamanho e melhor encadernação, indicando que ela convive com pessoas familiarizadas com a alta cultura ou que suas leituras podem não se restringir aos romances, embora seja este 0 aspecto privilegiado pelo pintor. (ABREU, 2001, p. 144)
\end{abstract}

Os ícones da leitura, como os livros e as bibliotecas, davam a dimensão do ambiente cultural em que vivia a leitora. A partir dessas imagens, construíram-se discursos que fundamentam um Brasil de não-leitores. Todavia, com o advento da era eletrônica, tais ícones, cujo amparo se firma no livro impresso, perdem, de certa forma, o sentido, uma vez que tempo, materialidade e espacialidade são postos em discussão. Na dinâmica do tempo, presente, passado e futuro do livro - enquanto materialidade impressa - se confrontam na era digital. O período alongado que demandava acúmulo, aquisição e preservação de poder e de saber se perde. O espaço físico e fixo da biblioteca se esvai. A privacidade na esfera coletiva e a coletividade no espaço público ganham dimensões inimagináveis, impossíveis de se apreender, de se estabelecer como fixação de um lugar próprio de estar. A aldeia global se interliga pela conexão em rede em que o público e o privado se interrelacionam.

Novamente, similaridades e diferenças marcam o texto impresso e digital. $\mathrm{Na}$ dinâmica da leitura, a interação mencionada por Bakhtin, embora concretizada pela prática do ato de ler, não é materializada no texto impresso, porque ele não permite isso. A delimitação da escrita no papel, a definição dos papéis sociais bem marcados, como autor, leitor, editor, dentre outros, limita uma intervenção materializada. Vale destacar que Bakhtin não se ateve a essa discussão. Ele buscou entender a linguagem. E, por esse embasamento teórico, é possível defender que ler e escrever são modos de intervir no mundo. Mas isso não supõe um colocar-se como registro literal no texto. 
O texto impresso, em forma de livro, se apresenta limitado pela não intervenção do leitor nessa materialidade. Isso pressupõe a definição de lugares - o lugar do escritor e o lugar do leitor, por exemplo. O leitor, embora tenha sido pensado pelo escritor, pelo diagramador, pelo impressor, pelo livreiro no próprio circuito do livro, tal qual expõe Darnton (2010), materializado nos aspectos tipográficos de uma obra, é idealizado. Não é ele o leitor real. O reconhecimento da ocupação de certos lugares garante a legitimidade da propriedade do texto por meio da autoria. O escritor detém, porventura, o texto que produz. Na dinâmica da relação leitor e texto, o dialogismo ocorre pelas implicações geradas pelo texto no leitor, diferentemente da intervenção direta ocasionada com o advento do texto eletrônico, na qual se mesclam o papel do leitor e do escritor, do leitor e do impressor. O surgimento do termo "escrileitura" talvez sintetize um pouco desse processo de fusão de papéis na relação entre leitor e texto.

\section{Leitor, texto e leitura na era digital: o processo de "escrileitura"}

O advento da cibercultura, especialmente com a popularização do Personal Computer (PC) e das redes sociais de compartilhamento na Internet, expandiu as possibilidades de produção cultural e artística, diversificando, consequentemente, as experiências de leitura. Nessa ambiência, deu-se uma emergência significativa de gêneros textuais em rede, textos que se originam e se modificaram vertiginosamente no ambiente colaborativo da Web. Torna-se, então, cada vez mais evidente $o$ fato de que a sociedade contemporânea tem sido marcada por fluxos informacionais que garantem a comunicação fluida e constante, alterando comportamentos comunicativos, tanto de emissão quanto de recepção. Vivenciase a linguagem e $\mathrm{o}$ ato comunicativo em rede. Isso acabou por subverter as fronteiras existentes entre emissor e receptor, o que, consequentemente, afeta as produções de leitura e escrita. Os atores desse processo (autor, leitor, canal, mensagem...) e as funções que os determinavam, bem como as relações entre estes na construção elocucional do texto, deixaram de ser percebidos com demarcações claras, uma vez que os textos digitais se tornaram extremamente mutáveis e assumiram um caráter dinâmico e proteiforme. 
Uma questão que se impõe, nesse contexto, é: Até que ponto a leitura se encontra em interação com a mídia computacional e quais os efeitos dessa interação? Nesse particular, assinala Hayles (2009), o fato curioso de que todo e qualquer texto hoje, antes mesmo de assumir seu formato definitivo "no papel", passa pelo processo de "digitalização". Portanto, escrever e, consequentemente, ler ao computador tem se tornado uma condição inevitável em todo processo de produção e recepção de textos na sociedade contemporânea.

Desta forma, a própria diferenciação entre materialidades de textos se confunde, pois é possível verificar "ferramentas" em textos impressos, a modelo das criadas pelos textos digitais. A obra Ladrões de histórias, de João Anzanello Carrascoza, revela isso. Fonseca (2009), ao analisar essa obra, enfatiza que os capítulos do livro são interligados em forma de links, marcados à semelhança do texto digital, pelo sublinhado em palavras-chave. Os caminhos possíveis da narrativa são apresentados ao leitor por um mapa impresso em uma das páginas da obra, que o leitor precisa decifrar. $\mathrm{O}$ texto impresso, que antes conduzia o leitor $\mathrm{e}$, inclusive, dialogava com ele diretamente, assegurando sua permanência, como as obras de Machado de Assis e outros escritores brasileiros, agora the concede a liberdade para seguir outros percursos².

Algumas ferramentas interativas manifestadas na obra de Carrascoza garantem, de certo modo, também a permanência do leitor em diálogo com os propósitos do texto, a exemplo de lançamentos de "advinhas", as quais possibilitam a abertura de novos capítulos que são descobertos por dicas decorrentes de ilustrações. A dinamicidade ofertada por tais ferramentas assegura mobilidade na relação entre leitor e texto e expõe uma multiplicidade de linguagens verbais e não-verbais, as quais o leitor precisa "decifrar". Desta forma, antes constituído por uma materialidade fixa, anteriormente oralizada ou apreendida silenciosamente, o texto ganha uma dimensão fluida e desestabilizante.

\footnotetext{
${ }^{2}$ Para conhecer como se estabelece o diálogo com o leitor em obras literárias, ver Lajolo e Zilberman (1996).
} 
Com efeito, na sociedade contemporânea, é possível perceber que a sucessão da oralidade e da escrita pelas novas formas de percepção do hipertexto é uma maneira de gerenciar o conhecimento, que não se dá pela simples substituição de modelos culturais e tecnologias. Isso se dá porque o hipertexto, em sua complexidade estrutural, desloca o centro de circulação de informação para as redes de significações discursivas (FERRARI, 2010). Segundo Ferrari (2010), "o hipertexto é um conjunto de nós de significações interligados por conexões de palavras, páginas, fotografias, imagens, gráficos, sequências sonoras etc." (FERRARI, 2010, p. 74). É assim que as narrativas digitais superam as limitações da oralidade e da escrita, posto que, em vez de fragmentarem o sentido do texto ou do discurso, isolando-o do leitor, antes, ampliam sua rede de significações, aproximando mais ainda o leitor da construção do significado.

Nesse âmbito, surge também, no processo de criação literária, uma espécie de cumplicidade entre o autor e o computador, uma vez que este último participa do processo criativo como um instrumento manipulador de signos verbais e como elemento ativo da produção do texto. É assim que, na visão de Barbosa (2001), o computador se torna uma máquina semiótica, uma vez que ultrapassa os limites do simples armazenamento de informações (função que, no entanto, ainda conserva) e, por isso, participa ativamente da ação criativa do texto. A esse respeito, esclarece, ainda, Barbosa que o processo comunicacional da leitura altera-se consideravelmente, tanto no aspecto da produção quanto da recepção do texto, uma vez que, ao tornar-se interativo, envolve a participação do leitor na coautoria do texto final, por meio de "um processo simultâneo de escrita-leitura: a escrileitura" (BARBOSA, 1996, p.2). Esse fenômeno interfere nas condições de produção do texto eletrônico, estabelecendo novas categorias de leitura e procedimentos de escrita. A fusão entre essas duas facetas provoca o que o autor denomina "escrileitura", "o que pode mesmo exigir um termo novo para designar a figura cooperativa do 'escrileitor' (wreader/laucter)" (BARBOSA, 1996, p. 37). Segundo esse autor, para além de um instrumento de criação literária, o computador passa a ser também um instrumento de leitura, uma vez que a interposição da máquina, enquanto "manipulador de sinais e extensor de complexidades", acarreta uma nova atitude do autor e do leitor frente à obra 
computacional. O leitor participa, então, do processo criativo, num verdadeiro ato de "co-criação", donde se reafirma a figura do "escrileitor" - "aquele que pratica a leitura pela escrita e a escrita pela leitura, numa nova simbiose interactiva". (BARBOSA; CAVALHEIRO, 1996, pp. 10, 11).

Um exemplo dessa escrita criativa é a "construção" narrativa de Tecelina, desenvolvida pela Pontifícia Universidade Católica do Rio Grande do Sul, sob a coordenação da professora e pesquisadora doutora Vera Teixeira de Aguiar, disponível no endereço da ediPUCRS. Baseada na obra Tecelina, de Gláucia de Souza, o grupo de trabalho, coordenado pela professora mencionada, constroi seu texto a partir de ferramentas variadas, como clicar do mouse para ingresso em links que definem caminhos para a narrativa, arrastar textos e objetos para construir sentidos e montar cenários ou o clicar em imagens para musicalizar ambientes. Essas ferramentas asseguram estratégias para que o leitor se sinta participante da narrativa.

A interação entre leitor e texto, mediada por essas ferramentas, comunga práticas de leitura que ora silenciam ora se oralizam, e, no caso dessa história, independe de a criança ter domínio ou não da língua. Isso ocorre porque ela vai interagindo com o texto, arriscando, e por isso conhecendo, e por isso brincando, fruindo, aprendendo. Nessa brincadeira de descobertas e revelações, os sentidos sobre a língua são por ela construídos. Há trajetórias também que permitem a intervenção direta da criança na produção de certas palavras ou até de textos. Os caminhos da narrativa projetam, portanto, diferentes leitores em interação com o texto.

No entanto, tais ferramentas, que dão liberdade ao leitor, não se efetivam na obra impressa, cuja sustentação gerou a narrativa de Tecelina, desenvolvida pela PUC do Rio Grande do Sul. No livro Tecelina, escrito por Gláucia de Souza, diferentemente do que ocorre em Ladrões de história, a narrativa segue um caminho linear, sem ferramentas ou quaisquer marcas que mesclem suporte impresso e digital. Desse modo, o projeto da PUC transformou a obra impressa em texto digital. Manteve-se, para isso, a essência da narrativa e se estabeleceu um jogo marcado por tópicos temáticos norteadores para o desenrolar da história, 
como a questão dos tempos históricos e o tecer da própria vida. Embasado nesses dois eixos, o projeto desenvolvido a partir do livro impresso permite que o leitor adentre o passado da personagem pela história de seus avós, o presente e o futuro de Tecelina. Nesse revisitar de tempos históricos, a reflexão sobre a existência humana é instigada como se o tecer, típico das histórias míticas (numa alusão às Parcas ou a Penélope), fosse uma prática individual, mas também conjunta, coletiva, porque agrega valores, tradições que são, acima de tudo, herdadas e, portanto, consistem em construções sociais.

Por isso, na passagem de um texto impresso ao digital, no jogo que ali se estabelece, como no exemplo de Tecelina, muitos discursos se agregam e anunciam outras paradas, inclusive anunciam caminhos ainda não traçados. $O$ leitor, nesse percurso, se encontra, porque se identifica com uma história que é dele, mas que é também universal. Uma história que se ampara numa materialidade, mas que ganha fluidez e dinamicidade a partir de um entrecruzar de som, movimento e cores, o que caracteriza os novos tempos. Nesse enfoque, defende, ainda, Lévy ( 2011, p. 41, /grifos do autor/) que:

\begin{abstract}
O leitor em tela é mais "ativo" que o leitor em papel: ler em tela é, antes mesmo de interpretar, enviar um comando a um computador para que projete esta ou aquela realização parcial do texto sobre uma pequena superfície luminosa. [...] Na verdade, é somente na tela, ou em outros dispositivos interativos, que o leitor encontra a nova plasticidade do texto ou da imagem, uma vez que, como já disse, o texto em papel (ou o filme em película) forçosamente já está realizado por completo. A tela informática é uma nova "máquina de ler", o lugar onde uma reserva de informação possível vem se realizar por seleção, aqui e agora, para um leitor particular. Toda leitura em computador é uma edição, uma montagem singular.
\end{abstract}

Nesse universo de dimensão singular, mas social, esse novo modo de ler, ancorado em ferramentas que permitem a mobilidade do leitor na construção dos sentidos, revela um leitor que participa da própria edição e montagem do texto. Tal prática não nega o passado, mas põe em cena, nas etapas de construção do livro, a determinação de lugares. Corrobora tal defesa Chartier (2007, p. 21), quando diz que o texto digital exige uma reorganização da "economia da escrita", uma vez que: 


\begin{abstract}
Ao tornar a produção, transmissão e leitura, de um dado texto, simultâneas, e ao atribuir a um único indivíduo as tarefas, até aqui distintas, de escrever, publicar e distribuir, a apresentação eletrônica dos textos anula as antigas distinções entre papéis intelectuais e funções sociais. [...] Estas incluem os conceitos jurídicos (direitos autorais, propriedade literária), categorias estéticas (originalidade, integridade, estabilidade), noções administrativas (biblioteca nacional, depósito legal) e instrumentos bibliográficos (classificação, catalogação, descrição), os quais vinham sendo usados até agora para caracterizar o mundo escrito.
\end{abstract}

Nesse contexto, há certamente uma inegável diferença entre a escrita linear e analógica dos leitores do livro, qual seja, a da página impressa, e a leitura dinâmica e dialógica, feita pelos internautas de hoje, na tela do computador. Neste, tanto a noção de autoria quanto a de leitor se modificam, pelas próprias condições da interatividade envolvida. No computador, o espaço de escrita é a tela, ou a janela, ao contrário do que ocorre quando o espaço da escrita são as páginas do papel. A escrita na tela possibilita a expansão do texto no papel, redefinindo as características performáticas do hipertexto, que é, segundo Lévy (2000, p. 61), "um texto móvel, caleidoscópico, que apresenta suas facetas, gira, dobra-se e desdobra-se à vontade frente ao leitor".

É esse novo modo de recepção do texto que nos dá uma ideia clara desse painel que esboça, na língua inserida em suas práticas sociais efetivas, as mudanças culturais que acarretam uma multiplicidade de linguagens configuradas nos ambientes do meio público ou privado. No dizer de Bauman (2001), o ambiente social passou a caracterizar-se pela maleabilidade das relações e das instituições, uma vez que, gradativamente, perderam-se as referências de elementos que pudessem ser percebidos como sólidos e fixos nos processos sociais. Da mesma forma, Castells (2002) nos adverte sobre a formação de uma rede social na qual a construção de identidades e o alinhavar das individualidades se dá de maneira diferenciada à dos períodos anteriores da história ocidental, como se buscou demonstrar neste texto. 


\section{Conclusão}

Ao fechar o ciclo de nossas reflexões, é possível inferir que os percursos do leitor, do livro - impresso ou digital - e da leitura foram se configurando em vivências interativas que permitiram aos indivíduos se agregarem, a partir de interesses diversos, e se expressarem simultaneamente, de forma sincrônica e anacrônica, na construção de novas modalidades de texto e de experiências singulares de "escrileitura".

Vale lembrar que o avanço tecnológico é decorrente de transformações sociais, na medida em que a própria complexidade da vida moderna impõe como desafio aos leitores um defrontar-se com inúmeros gêneros textuais, linguagens verbais e não-verbais. A rigor, a história do livro ou da escrita, em suas diferentes materialidades, lança como desafio um revisitar permanente da relação entre leitor e texto, numa realidade que cada vez mais se desterritorializa e se torna fluida.

A multiplicidade de sentido gerada pela mudança do livro, do impresso ao digital, não é mais decorrente de um "registro" ofertado ao leitor, uma vez que este participa da dinâmica de construção do texto e intervém no cenário que fomenta outros sentidos, tornando público esse texto que se elabora por inúmeras mãos, inclusive desconhecidas entre si. São leitores-autores "anômimos", diferentemente dos autores-heróis que rompem com a delimitação do público e do privado e assumem funções sociais antes prescritas e delimitadas.

Efetivamente, os papéis intelectuais e as funções sociais que caracterizam a história do livro ganham novas dimensões na relação entre leitor e texto na era digital. Inclusive o almejo de uma biblioteca universal tal qual o modelo de Alexandria torna-se possível, porque tempo e espaço assumem outras caracterizações.

No entanto, o desenrolar da relação entre leitor e texto só foi possibilitado porque uma trajetória histórica de desenvolvimento humano, materializado na linguagem, 
em seus diferentes formatos, anunciou, como ainda anuncia, novos percursos de participação social, de intervenção na realidade, que exige um olhar cada vez mais cuidadoso para as práticas em que o leitor se constitui como sujeito.

\title{
RESOURCES OF READING BETWEEN THE PAGE AND THE SCREEN: A MULTIPLICITY OF MEANINGS
}

\begin{abstract}
This article draws an outline of the social practices of reading while proposing a discussion on the conditions of production and reception of digital texts. It does so by focusing the relationship between the reader and the text in analogical and digital reading experiences, evaluating their particularities on the materiality of the text and its configuration in these media. It takes into account the multiple constructions of meaning which are possible to the reader in contact with the text, in view of the way he/she grasps the printed text and how that changes when it comes to text in digital media since in this case the text and the reader are interconnected by technologies which make possible the convergence of media and intensify the experience of reader's interaction with the text and the interface.
\end{abstract}

KEY WORDS: Reading. Printed text. Digital text. Reader. Interactivity.

\section{Referências}

ABREU, M. Diferença e desigualdade: preconceitos em leitura. In.: MARINHO, M. (Org.). Ler e navegar: espaços e percursos da leitura. Campinas, SP: Mercado das Letras: Associação de Leitura do Brasil (ALB), 2001.

AGUIAR, Vera Teixeira (Coord.). Tecelina. In: Ler e brincar: atividades de leitura literária com jogos de construção narrativa. Dados eletrônicos. Porto Alegre: $\quad$ EDIPUCRS, 2008.2 Disponível em $<$ http://www.pucrs.br/edipucrs/lerebrincar narrativa/lerebrincar narrativa.swf $>$. Acesso em 3 março 2012.

BAKHTIN, Mikhael (Volochínov). Marxismo e filosofia da linguagem: problemas fundamentais do método sociológico da linguagem. Tradução de Michel Lahud e Yara Frateschi Vieira. 13. ed. São Paulos: Hucitec, 2009.

BARBOSA, Pedro. A Ciberliteratura: criação literária e computador. Lisboa: Cosmos, 1996.

. O computador como máquina semiótica. In: Revista de Comunicação \& Linguagens. Lisboa, Universidade Nova de Lisboa, n. 29, abr/2001. Disponível em <www.pedrobarbosa.net $>$. Acesso em 20 maio 2012.

; CAVALHEIRO, Abílio. Teoria do homem sentado. Porto: Edições Afrontamento, 1996. 
BARBOSA, Raquel Lazzari Leite. A construção do "herói". In: Leitura na escola: Assis - SP - 1920 a 1950. São Paulo: Editora UNESP, 2001.

BAUMAN, Zygmunt. Modernidade líquida. Rio de Janeiro: Zahar, 2001.

CASTELLS, Manuel. O poder da identidade. São Paulo: Paz e Terra, 2002.

CERTEAU, Michel de. A invenção do cotidiano: artes de fazer. 11 ed. Tradução Ephraim Ferreira Alves. Petrópolis, RJ: Vozes, 2005.

CHARTIER, Roger. A aventura do livro: do leitor ao navegador: conversações com Jean Lebrun/Roger Chartier. Tradução Reginaldo Carmello Corrêa de Moraes. São Paulo: Imprensa Oficial do Estado de São Paulo: Editora Unesp, 2009.

As revoluções da leitura no Ocidente. In: ABREU, Márcia (Org.). Leitura, história e história da leitura. Campinas, SP: Mercado das Letras: Associação de Leitura do Brasil; São Paulo: Fapesp, 2007. (Coleção Histórias de Leitura)

DARNTON, Robert. O beijo de Lamourete: mídia, cultura e revolução. Tradução de Denise Bottmann. São Paulo, São Paulo: Companhia das Letras, 2010.

FERRARI, Pollyana. Hipertexto e hipermídia: as novas ferramentas da comunicação digital. São Paulo: Contexto, 2010.

FONSECA, Juliana Rangel. Perspectiva de leituras em Ladrões de histórias de João Anzanello Carrascoza. Anápolis: Universidade Estadual de Goiás Faculdade de Educação, 2009.

HAYLES, N. Katherine. Literatura eletrônica: novos horizontes para o literário. São Paulo: Global. 2009.

LAJOLO, Marisa; ZILBERMAN, Regina. A formação da leitura no Brasil. São Paulo: Editora Ática, 1996.

LEITE, Sérgio Antônio da Silva; OLIVEIRA, Lilian Ricarte. Constituição do leitor: análise dos eventos de leitura no curso de pedagogia da Unicamp. In: Revista Leitura: teoria \& prática. ano 22, № 42, p. 19-32. Campinas: 2004.

LÉVY, Pierre. As tecnologias da inteligência: o futuro do pensamento na era informática. Lisboa: Instituto Piaget, 1990.

. Cibercultura. Lisboa: Instituto Piaget, 2000.

. O que é virtual? (Coleção TRANS). 2. ed. São Paulo: Editora 34, 2011.

MARQUILHAS, Rita. Leitura: um silêncio recente. In: Leitura: teoria \& prática. ano 18, n. 33, jun, 1999. 
MELO, Orlinda Carrijo. A invenção da cidade: leitura e leitores. Goiânia: Ed. da UFG, 2007.

NORA, Pierre. Entre memória e história: a problemática dos lugares. In: Projeto História - Revista de Estudos Pós-Graduados em História e Departamento de História da PUC-SP, no 10, pp. 7-28, 1993.

POMPOUGNAC, Jean-Claude. Relatos de aprendizado. In: FRAISSE, Emmanuel; POMPOUGNAC, Jean-Claude; POULAIN, Martine. Representações e imagens de leitura. São Paulo: Editora Ática, 1997.

SOUZA, Gláucia de. Tecelina. Ilustrações de Cristina Biazetto. Porto Alegre: Editora Projeto, 2002. 